\title{
Fire severity prediction analysis of a traditional libya house roofing materials: A case study
}

\author{
M. Mkharem ${ }^{1}$, N. M. Adam ${ }^{1}$, E.E. Supeni ${ }^{1}$ and S. Mustapha ${ }^{2}$ \\ ${ }^{1}$ Department of Mechanical and Manufacturing Engineering \\ ${ }^{2}$ Department of Chemical and Enviromental Engineering \\ Faculty of Engineering, Universiti Putra Malaysia, \\ 43400 Serdang, Selangor, Malaysia \\ *Email: mufida_mln@yahoo.com \\ Phone: +601136493553
}

\begin{abstract}
Most recorded Libya house fire accidents are associated with the types of roofing materials used in the building of the traditional Libya houses, mainly from the date palm trees (DPT) parts. This research focuses on the fire characteristic properties of DPT building material based on four conducted laboratory experiments on the preprocessed known mass of leaves, trunk, and root samples collected across 40, 41, 80, and 81 years old trees, across different geographical location in Libya. The characterisation analyses result of calorific energy contribution of $4107.2 \mathrm{cal} / \mathrm{gram}$ from older DPT trunk samples, percentage weight loss reduction of $-2.2 \mathrm{mg} /{ }^{\circ} \mathrm{C}$, at the highest temperature range of 727$899{ }^{\circ} \mathrm{C}$ from thermogravimetric test. The highest diffusivity rate of $0.138 \mathrm{~mm}^{2} / \mathrm{s}$ also occurs at $99-100^{\circ} \mathrm{C}$ on the oldest trunk sample, and fire propagation index of 0.0463 was recorded with index performance of $32.3^{\circ} \mathrm{C}$. These result analyses indicated high heat conductivity at a lower temperature, fast heat rate of propagation to support fire accident when in contact with fire flame, and high calorific load value for fire growth in traditional Libya houses. Useful information on rate of heat conductivity, fire propagation properties, and thermal behaviours of DPT for fire impact assessment analyses prediction in traditional Libya houses.
\end{abstract}

Keywords: Date palm tree; fire safety; fire propagation; calorimetric

\section{INTRODUCTION}

Fire accidents cause unexpected damages to lives and properties of inhabitants of any affected resident due to direct exposure to heat and poisoning smoke inhalation of toxic gases released from burning materials during combustion $[1,2]$. The science that deals with the act of prevention and mitigation of unwanted fire eruption is called fire safety $[3,4]$. This helps to limit the extent of injuries to lives and damages to properties to the barest minimum as proposed $[3,5]$. The fire severity prediction can be expressed as a function of factors associated with the number of combustible materials available in the room, room size geometry, heat loss level of the surrounding, room surface thermal properties, emissivity of the flames in the room, and characteristic size of available ventilation of the room $[6,7]$. In predicting study of fire accidents, two critical parameters must be known which are fire load contents and the room ventilation characteristics [1, 8-10]. Fire load is the starting point for the estimation of the possible fire potential size 
[11], and severity without much consideration to the available ventilation characteristic [12]. Earlier studies from the literature applied only measured mass and calorific value of the fire load contents [1, 13-19]. However, this study could not determine the thermal conductivity properties of the DPT with respect to heat conduction and propagation [2022]. This study proposed a fire severity prediction of a traditional house with additional three thermal characteristic property test analysis on DPT roofing materials used in the residential buildings in Tripoli, Libya. This will help put in place adequate proactive measure to mitigate unwanted fire disasters that may likely happen in future.

Traditional houses are mostly found in rural areas as a unique settlement for ethnic people as also seen in Tripoli, Libya. The largest cluster of traditional houses is located mostly in old cities, but the old style of building can be found in other parts of the modern cities across the nation. Most recorded Libya fire accidents are associated majorly with the types of materials used in the traditional building structures. These are mainly items from old DPT as displayed in Figure 1(a) and (c) [23]. In addition, most constructed traditional building in the country does not comply with any known safety standards, like the fire safety standards $[16,24]$. However, the nature of dry wind in winter season tends to mistakenly blow most of the alternative illuminating sources (candles) provided due to the epileptic power supply from utility companies in contact with the highly combustible material, thereby creating undesired fire accident. This may engulf the entire house if not discovered and controlled on time. The main reason for this is due to the extremely dry and high temperature within this winter period. In addition to this, lack of fire safety knowledge awareness and the associated danger increases the frequency of fire accident occurrence, hence, the need in order to reduce fire accidents among traditional houses in Libya and the impending dangers on human lives and properties. These proposed fire characteristic properties of DPT roofing material are needed to predict the fire load calorific value, heat conductivity properties, and fire propagation level of DPT as a traditional roofing building material. This study assisted in the determination of safety assessments required for the traditional Libya house compliance with the world fire safety standard [25] since the cost of removing embedded roofed DPT or rebuilding most of these old traditional building is enormous and requires lots of manpower engagements and sound technical know-how. This study provides some helpful knowledge needed for preventive and proactive fire safety measures against unwanted fire accident [26].

In view of these stated problems, this research focused on predicting the fire characteristics of DPT building material applied in the construction of traditional Libya houses. The characterisation is based on the heat of combustion, percentage loss of weight, conductivity, and diffusivity tests as proposed to be carried out on selected DPT samples of leaves, trunk, and roots. The approximate ages of the few selected samples as proposed are determined by counting the number of tinny bands with each ring representing an annual growth in diameter on the wood cylinder, which determined the estimated age of the DPT as displayed in Figure 1(a) or with the application of portable Increment borer instrument [27]. Three DPT sample parts were collected based on average, and maximum age values of $40,41,80$, and 81 years across different geographical locations in Libya.

\section{EXPERIMENTAL SETUP}

\section{Design of Experiment}

DPT is an economic tree cultivated based on its edible fruit it produces. It has a tall cylindrical trunk of between 10-15 m, without any branching stem and with constant 
diameter from the base to the crown. DPT is made-up of vascular bundles held together with connective tissue at the top with embedded leaves [27]. The length and age depend on so many factors amongst which are the regional weather, climates, rainfalls, and age ranging between 80-100 years. This approximate age is determined by the number of rings as displayed in Figure 1 (a) of a cut sample trunk, which gives a rough estimation of the age as proposed. The approximate ages of the few selected samples as proposed are determined by counting the number of tinny bands, with each ring representing an annual growth in diameter on the wood cylinder which determined the estimated age of the date palm as displayed in Figure 1 (a) [27].

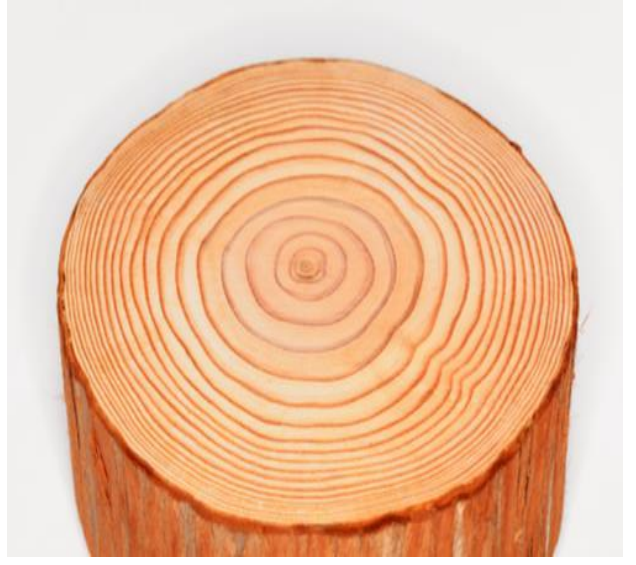

(a)

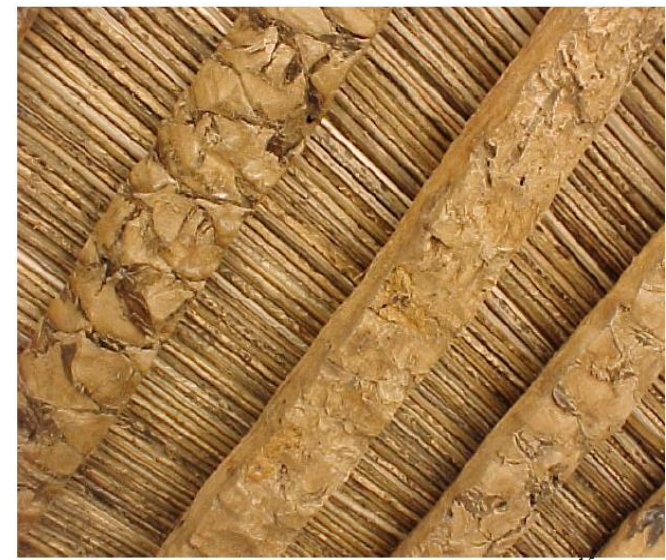

(b)

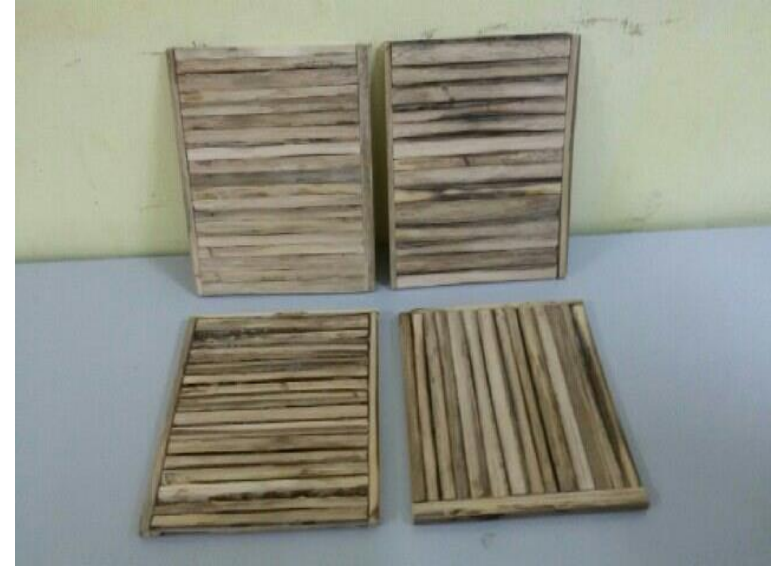

(c)

Figure 1 (a) DPT trunk cross section, (b) Libya Traditional roof with date palm trunk, and (c) DPT twig (from leaves)

The detailed procedure undertaken in the characterisation of the DPT sample from Libya is illustrated in Figure 2. This begins with the sample size selection of the date palm leaves, trunks, and roots from aged trees across Libya. These selected samples underwent the preprocessing stages of preparation to an acceptable standard, suitable for the four laboratory fire characterisation test experiments.

\section{Experimental Procedure \\ DPT samples preparations}

The selected DPT leaves, roots, and trunk samples taken from the 40, 41, 80, and 81 years old trees were kept tightly in a polyethylene bag at room temperature in a desiccator container to prevent moisture loss from the samples. Moisture is the major key parameter 
needed for the laboratory experiment as it is related to fire characterisation of property determination. These samples were tested at the Thermofluid Laboratory of the Mechanical and Manufacturing Engineering department of Universiti Putra Malaysia, Serdang Selangor. These sets of samples were grounded into powders as a requirement for fire conductivity test across all the samples. In order to perform calorimeter test, the samples were further made into pellets by pellet mechanical press. This is a standalone accessory that provides a convenient and most economical way of compressing powdery materials to pellets or tablets with little or no cost within the laboratory setup as compared to the tablet making machines [28].

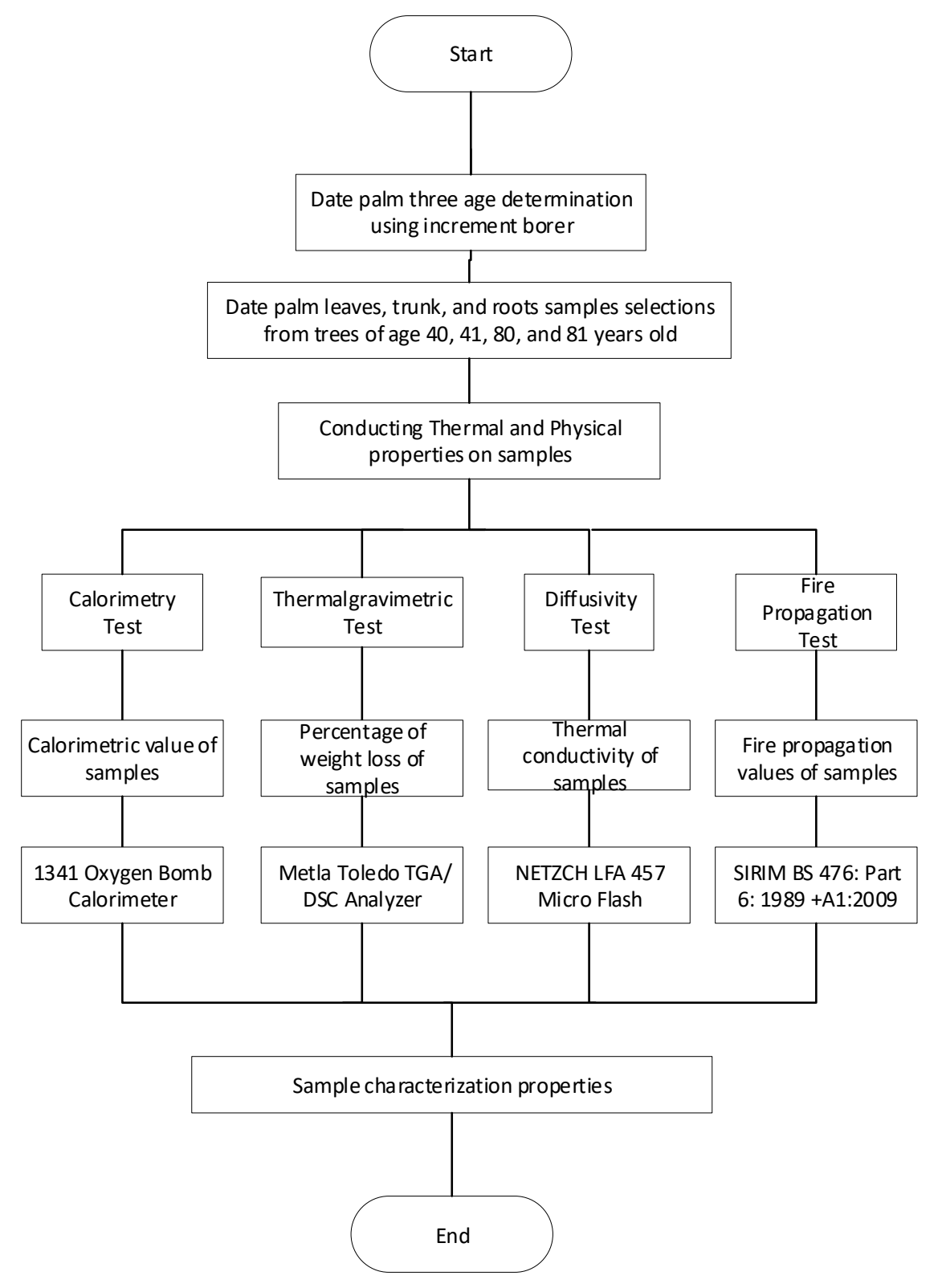

Figure 2 Characterisation flow chart of date palm tree samples

\section{Calorimetric test on DPT samples}

A specialised equipment called the calorimeter (1341 Oxygen Bomb Calorimeter) was used to determine the heat of combustion produced by a chemical reactions or physical 
changes on each test samples. There are several types of oxygen bomb calorimeter for different purposes with the simplest architecture consisting of a strong metal container sealed with the test samples in excess oxygen and ignited electrically. It was then suspended in a container filled with water with an attached thermometer to measure the heat of combustion generated at constant volume due to the temperature rise on the sampled material. The calorific value content of each sample was determined from the similar experiment as also proposed earlier [29].The heating values for three replicates of the proposed DPT samples across four age groups categories in a laboratory experimental test were determined with a bomb calorimeter. Moisture content is a crucial factor in determining the amount of useful heat from biomass combustion because the water is evaporated before the heat is available for the test application [30]. The moisture content varies from one part of DPT to another, normally having the lowest moisture at the leaves, increases from stem to the root section part of the DPT [31]. The calorimetric properties across all tested samples determine the energy equivalent obtained from burning of a known weight samples to determine the corresponding temperature rise within a stipulated time interval. The obtained heat from each sample based on the laboratory experiment was determined by the product of the observed temperature rise and the energy equivalent of the calorimeter. The resulting outcome was then divided by the weight of the sample. The calorific value (heat of combustion) of each sample was obtained on a unit weight basis. Considering the leaves' sample weight of 0.8 gram produced at a temperature rise in the calorimeter during the laboratory experiment measurement record with an energy equivalent value of $2416 \mathrm{cal} . /{ }^{\circ} \mathrm{C}$. The product of the temperature rise value with the obtained energy equivalent value, and divided by the samples weight, produces the heat of combustion across the leaves, trunks, or roots DPT samples as expressed in Eqs. (1) and (2) [31] for DTP of leave samples from age 40 years and temperature measurement in Table 1.

Table 1 Leaves' sample temperature rise measurement

\begin{tabular}{ccccc}
\hline \multirow{2}{*}{ Time sec) $)$} & \multicolumn{4}{c}{ Temperature measurement $\left({ }^{\circ} \mathrm{C}\right)$} \\
\cline { 2 - 5 } & 40 YRS & 41 YRS & 80 YRS & 81 YRS \\
\hline 0 & 30.28 & 30.28 & 31.1 & 31.14 \\
30 & 30.36 & 30.38 & 31.3 & 31.16 \\
60 & 30.64 & 30.65 & 31.56 & 31.48 \\
90 & 30.88 & 30.87 & 31.78 & 31.82 \\
120 & 31.08 & 31.09 & 31.86 & 31.98 \\
150 & 31.18 & 31.2 & 31.94 & 32.14 \\
180 & 31.26 & 31.25 & 31.98 & 32.2 \\
210 & 31.28 & 31.29 & 32 & 32.26 \\
240 & 31.3 & 31.31 & 32 & 32.28 \\
270 & 31.32 & 31.34 & 32 & 32.3 \\
300 & 31.32 & 31.34 & 32 & 32.3 \\
\hline
\end{tabular}

Change in temperature $(\Delta T)=$ Final temperature - Initial temperature

$$
\begin{gathered}
\Delta T=(31.32-30.28)=1.04{ }^{0} \mathrm{C} \\
\text { Calorific value }(\mathrm{Hg})=\frac{1.04 \times 2416}{0.8} \mathrm{cal} / \mathrm{g}
\end{gathered}
$$




\section{Determination of DPT SampleTthermal Properties}

This experiment illustrates the physical and chemical property changes of the date palm samples measured as a function of temperature increase with the constant heating rate or sample mass loss [31-33]. Thermogravimetric analysis (TGA) approach measures the change in weight of a sample as it is heated, cooled or held at a constant temperature to characterise sample materials with regard to its composition [34]. The information of the physical and chemical phenomena of the second-order phase transitions between the three states of matter can be provided by this test. Some selected characteristic features of the samples that displayed mass loss or gain due to decomposition, oxidation or loss of volatile moisture can also be executed with this test [31]. Other areas of applications include analysis of sample composition (ash and carbon black contents), sample dynamic decomposition, sample thermal stableness, oxidative stableness, moisture assessment and volatiles [27]. The thermal property determination for each selected sample of the DPT selected across proposed age categories for this research work was subjected to the TGA test. The application of a Perkin Elmer Thermal analyser Model no: TGA7/ DTA7 was deployed at a temperature range of $35-800{ }^{\circ} \mathrm{C}$ based on the previous fire simulation model [17] with a constant heating rate of $10{ }^{\circ} \mathrm{C} / \mathrm{min}$ with holding time of 1.0 minute at $35{ }^{\circ} \mathrm{C}$ under a nitrogen atmosphere.

Thermogravimetric analysis (TGA) measures the change in weight of a sample based on temperature changes in order to characterise the materials with regard to their composition [35]. The percentage weight loss of the date palm tree samples of leaves, trunks, and roots across all proposed age groups of 40, 41, 80, and 81 years were calculated with the application of Eq. (3).

$$
\text { Percentage weight loss }=\frac{\text { Weight loss at each phase }}{\text { Weight of total sample }}
$$

\section{Diffusivity Analysis Test on DPT Samples}

This experiment determined the heat transport properties of the date palm samples. This method is applied to characterise the sample property under varying heating condition; hence, illustrating how fast the sample responds to temperature changes in the environment. The diffusivity value of the sample must be known to predict any cooling process or temperature simulation effectively [30]. The rate of the temperature different propagation in these samples was determined through this analysis test by measuring the rate of temperature difference in each experimental sample. This is a thermo-physical property test mostly carried out with the use of Laser Flash (LFA) with NETZSCH having four models of LFA with higher spectrum coverage of the samples and temperature. The conductivity of each sample material was measured using the mean value of diffusivity denoted by $\alpha$ as illustrated by Eq. (4) [30]. The diffusivity of trunk sample of the DPT was measured using LFA with the sample mass of $0.08 \mathrm{~g}$ adopted in this diffusivity test and the obtained result for the diffusivity rate in $\mathrm{mm}^{2} / \mathrm{s}$ against the temperature rise is displayed in the result and discussion sections across all the aged categories.

$$
\text { Conductivity }(\mathrm{K})=\alpha \times \rho \times \mathrm{C}
$$

where, $\alpha$ is measured from a mean value of diffusivity $\left(\mathrm{mm}^{2} / \mathrm{s}\right), \rho$ is the density (mass/volume), and $\mathrm{C}$ is the specific heat capacity $(\mathrm{J} / \mathrm{kg})$.

Also, the Specific heat capacity, $\mathrm{C}$ is calculated using the Eq. (5);

$$
C=\text { Calorific value of sample } \times 10^{6} \mathrm{~J} / \mathrm{cal}
$$


Table 3. Result of sub-index and index of performance for specimen A, B, and C.

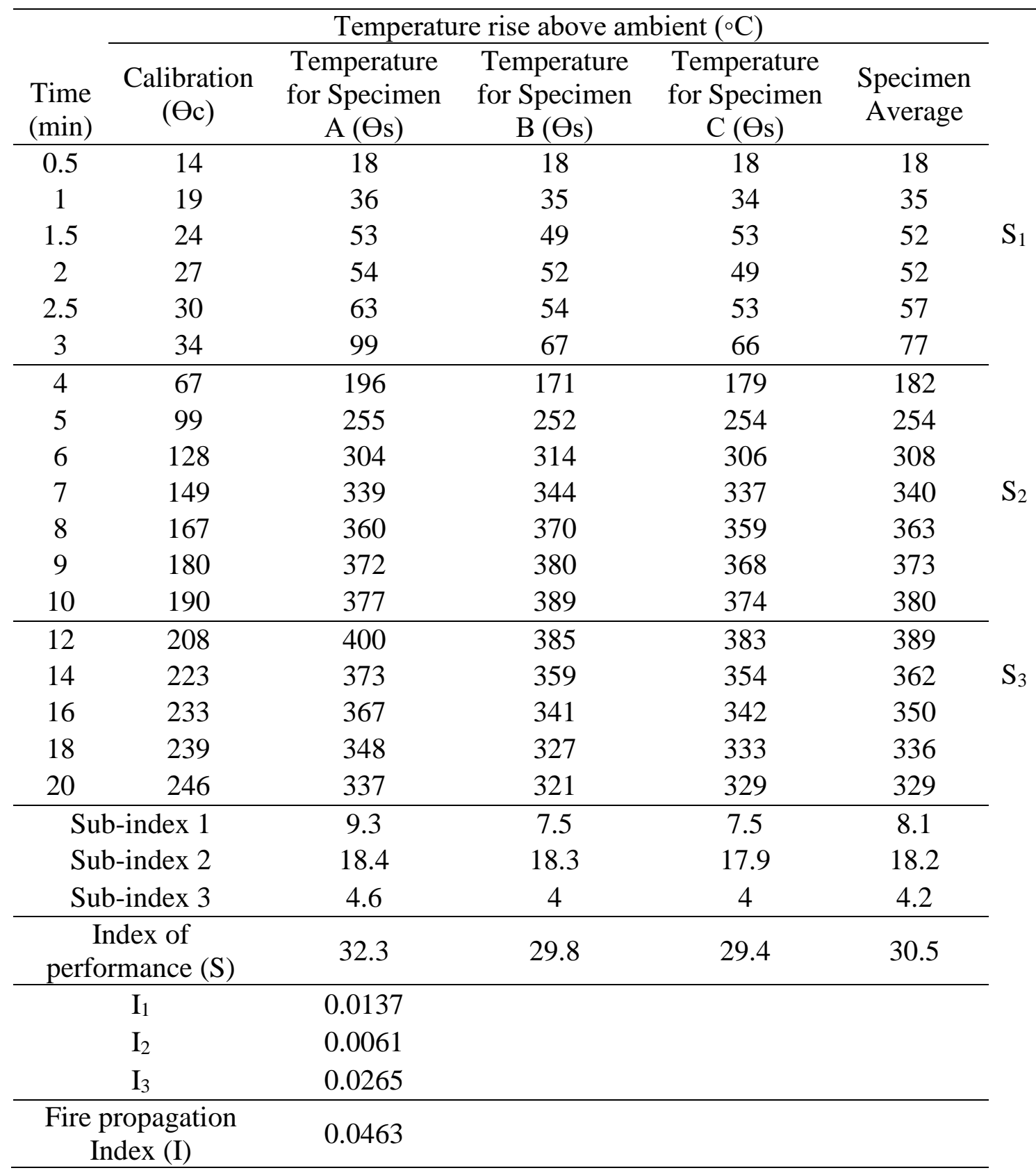

\section{Fire Propagation Test Analysis on DPT Samples}

This is the last fire characteristic property test carried out on the selected DPT samples to access the sample contribution to fire growth within an enclosed environment based on the heat release rate value of the samples. The sample mass loss and amount of oxygen consumed were measured in order to calculate the amount of heat release parameters. The fire response characteristic of each sample material was discovered with this analysis as published by [34]. The test sample description for fire propagation characterisation test with the 81 years old twig DPT sample was conducted using the thermocouple measuring instruments. The thickness of the sample measured was $8.7 \mathrm{~mm}$ and the density was 509 $\mathrm{kg} / \mathrm{m}^{3}$. The fire propagation test measurement was executed using the thermocouple instrument with reference to the test standard BS 476: Part 6: 1989+A1:2009. Three 
pieces of date palm twig of $225 \mathrm{~mm} \times 225 \mathrm{~mm} \times 8.7 \mathrm{~mm}$ (thickness) of dimensions from the 81 years old date palm tree were used for this experiment with the displayed result on Table 3 indicating the specimen $\mathrm{A}, \mathrm{B}$, and $\mathrm{C}$ sub-index performance measurement, the summary of the sub-index, and index performance, respectively. In addition to these, the calibration graph and the specimen average for 81 years old DPT are displayed in Figure 3 accordingly. The mathematical computational formula adopted for the index performance calculation as expressed in Eq. (6) is based on the sub-indices (S1, S2, and S3) calculations illustrated in equation. BS 476: Part 6: 1989+A1:2009.

$$
\text { Index performance }(S)=S_{1}+S_{2}+S_{3}
$$

where, $S_{1}=\sum_{t=0.5}^{t=3} \frac{\theta_{s}-\theta_{c}}{10 t} ; S_{2}=\sum_{t=4}^{t=10} \frac{\theta_{s}-\theta_{c}}{10 t} ; S_{3}=\sum_{t=12}^{t=20} \frac{\theta_{s}-\theta_{c}}{10 t}$

The mathematical formula used for the fire propagation index calculation across the samples are expressed with Eq.(7) BS 476: Part 6: 1989+A1:2009.

$$
\text { Fire propagation index }(I)=i_{1}+i_{2}+i_{3}
$$

where,

$$
i_{1}=\frac{1}{3}\left[\left(S_{1}\right)_{A}+\left(S_{1}\right)_{B}+\left(S_{1}\right)_{C}\right] ; i_{2}=\frac{1}{3}\left[\left(S_{2}\right)_{A}+\left(S_{2}\right)_{B}+\left(S_{2}\right)_{C}\right] ; i_{3}=\frac{1}{3}\left[\left(S_{3}\right)_{A}+\left(S_{3}\right)_{B}+\left(S_{3}\right)_{C}\right]
$$

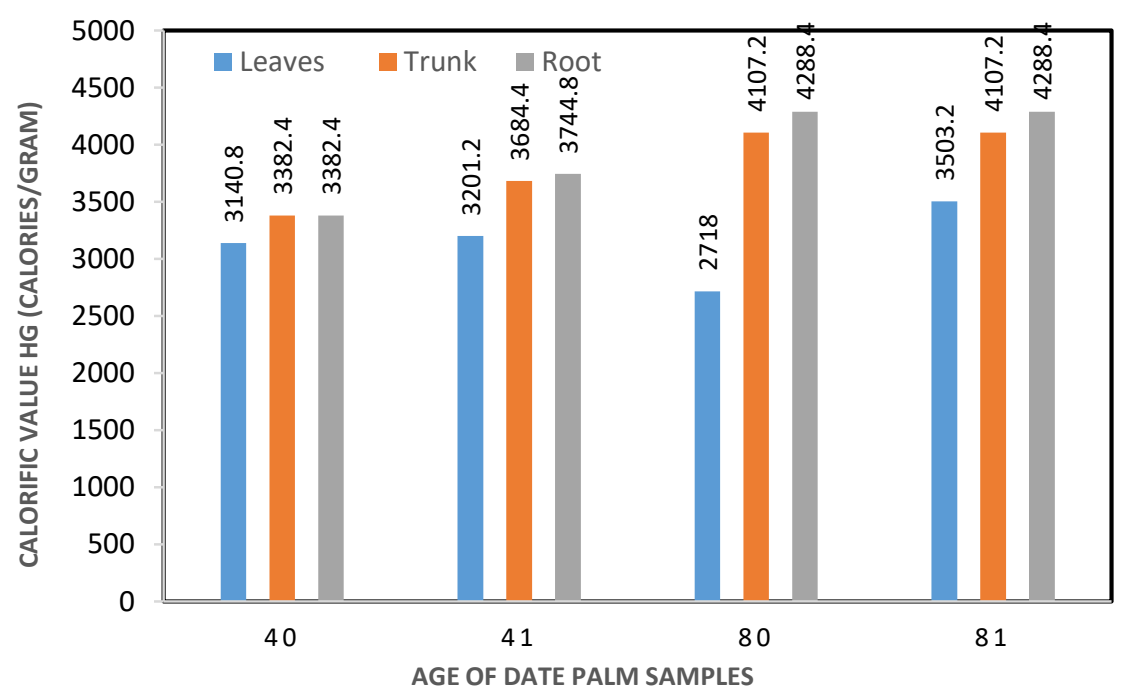

Figure 3. Calorific values of DPT samples.

\section{RESULTS AND DISCUSSION}

\section{Calorific Result of DPT Samples}

The sample calorific values from DPT were calculated using Eq. (1) and Eq.(2) with the result displayed in Table 2. Samples from DPT of 40 and 41 years indicated an increase in calorific values of $60.4,302$, and $362.4 \mathrm{cal} / \mathrm{g}$ for leaves, trunk, and roots samples, respectively. The energy release across all the samples depends on the moisture contents 
present in each sample with respect to the trees ages [32]. The available heating values from the samples were reduced based on the moisture contents, lowering the initial gross calorific value of biomass since heat was absorbed for the evaporation of water moisture contents in each sample; thereby, reducing the combustion efficiency [36].

Table 2. Calculated calorific value of DPT samples.

\begin{tabular}{lllll}
\hline Sample Description & \multicolumn{5}{c}{ Calorific Value $(\mathrm{Cal} / \mathrm{g})$} \\
\cline { 2 - 5 } & 40years & 41years & 80 years & 81 years \\
\hline Leaves & 3140.8 & 3201.2 & 2718 & 3503.2 \\
Trunk & 3382.4 & 3684.4 & 4107.2 & 4107.2 \\
Root & 3382.4 & 3744.8 & 4288.4 & 4288.4 \\
\hline
\end{tabular}

Moisture content is the most crucial factor in determining the amount of useful heat from any biomass combustion such as DPT because the water is evaporated before the heat is available for the test application $[2,31]$. This content varies from one part of DPT to another, normally having the lowest moisture at the leaves increased from stem to the root part. The moisture content was reduced as the age of the DPT samples increased from $40-81$ years [32-34]. Leave samples from DPT of age 80 and 81 years old produced $785.2 \mathrm{cal} / \mathrm{g}$ increment, which was much smaller compared to the higher values obtained from the trunk $4107.2 \mathrm{cal} / \mathrm{g}$, and roots samples $4288.4 \mathrm{cal} / \mathrm{g}$. This is because leaves easily evaporate its moisture and combust faster than any other parts of the three, thereby reduced the calorific value at a lower heating temperature as demonstrated earlier [37, 38]. The trunk, and roots produced the highest calorific energy value per unit gram of its sample across the obtained samples from trees of age 80 and 81 years as displayed pictorially in Figure 3. More heat energy contribution was produced from the older trunk samples in case of fire outburst. The individual temperature rose across all samples of leaves, trunk, and root is represented in a histogram of Figure 4.

\section{Thermogravimetric (TGA) of DPT Samples}

Thermogravimetric analysis (TGA) measured the change in state (weight) for each DPT sample with respect to temperature changes applied for the characterisation of the DPT samples based on their composition. The percentage weight loss of the DPT samples of leaves, trunks, and roots across proposed age groups of 40,41, 80, and 81 years was calculated using Eq. (3) indicated a thermal degradation of each sample in four stages as proposed earlier. These are hemicellulose, cellulose, lignin, and ash as proposed in earlier research publication [39]. The sequential decomposition stages for this research work as measured with incremental temperature changes are within temperature ranges of 45-123 ${ }^{\circ} \mathrm{C}, 210-300{ }^{\circ} \mathrm{C}, 160-900{ }^{\circ} \mathrm{C}$, and $1723^{\circ} \mathrm{C}$ as observed in the obtained result. Figure 4 and 5 display the percentage weight loss measured across all samples at each stage of temperature changes. These also produced an insight into different state changes that occurred during the TGA test. In addition, the comparative decomposition analysis study across 40 and 80 years old tree samples established that samples from trees older than 80 years old decompose faster than those from 40 years old trees with lesser weight losses due to higher moisture contents as displayed in Figure 5(a). Also, the similar relationship is displayed for samples taken from 41, and 81 years old trees but with a much higher value of weight loss from the older samples as the temperature increased due to lesser moisture contents [40, 41] and trees composition as displayed in Figure 5(b). The percentage weight loss was reduced as the temperature of the samples increased across 
all the samples, while the age of the samples also has a significant effect on the percentage quantity of weight loss. Thus, more weight was lost from older age DPT of age 41 and 81 years old because they decompose faster as compared to the younger samples from 40 , and 80 years across all leaves, trunks, and roots samples with respect to temperature increase as displayed in Figure 5(a) and (b). Generally, the thermal decomposition of these samples constitutes of four phases as established earlier [39]. The first phase was the moisture evaporation stage followed by the decomposition of lignocellulosic components of hemicellulose stage; next to this is the cellulose-lignin decomposition, and lastly the ash stage. Figure 6(a) and (b) illustrate the continuous weight loss progression behaviours across all samples with respect to temperature increment.

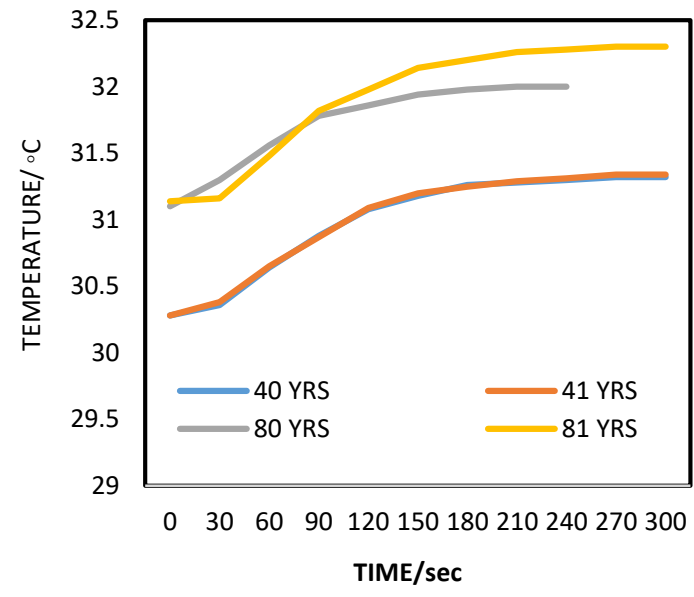

(a)

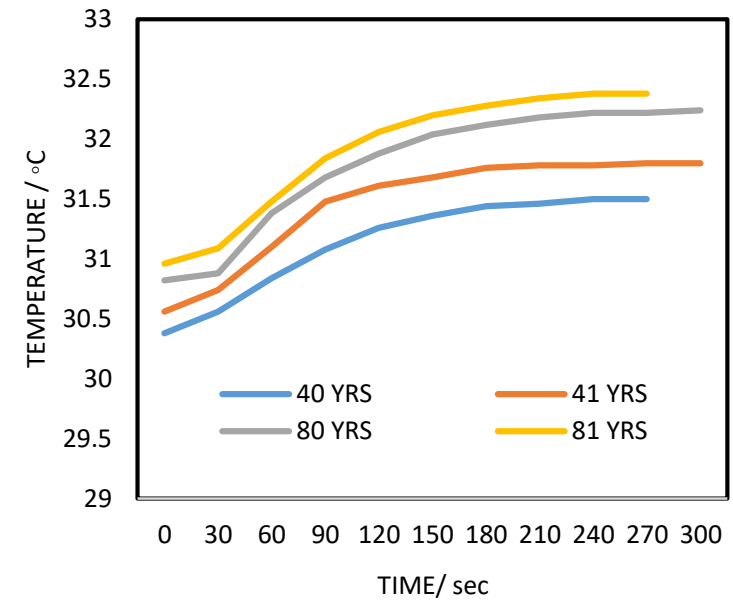

(b)

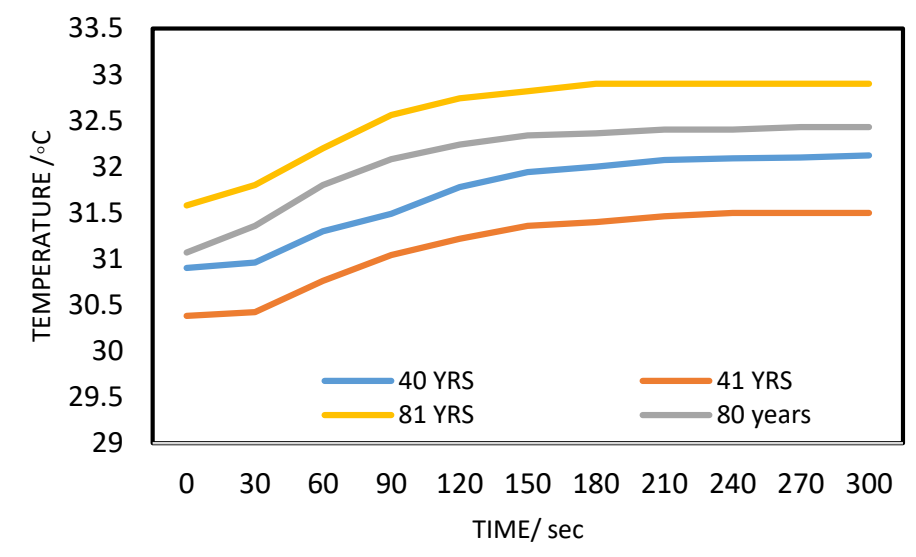

(c)

Figure 4. Rate of temperature rise measurement for (a) leaves, (b) roots, and (c) trunk samples of age of 40, 41, 80, and 81 years.

\section{Diffusivity Rate Result of Trunk Samples}

The result of the diffusivity test was applied to determine the thermal conductivity of the DPT trunk samples based on internal molecular bonding that exists within the molecular atoms of the sample. This encourages or hinders the heat conduction from the surrounding environmental temperature changes. The thermal diffusivity attributes of the roofing trunk samples are adopted for fire hazard prediction in this study. This is because the trunk is the major common roofing material of traditional Libya houses based on ease of 
availability and affordability. The obtained mean average results for the diffusivity rate in $\mathrm{mm}^{2} / \mathrm{s}$ across all samples with respect to the temperature rise are displayed in Figure 7(a) and (b). Particles from trunk sample ages 80 and 81 years demonstrated higher heat conduction from the environment due to their highest diffusivity values of $0.126 \mathrm{~mm}^{2} / \mathrm{s}$, and $0.138 \mathrm{~mm}^{2} / \mathrm{s}$, at a temperature range of $99-100{ }^{\circ} \mathrm{C}$, respectively as displayed in Figure 7(a). This is an indication of a less bond amongst the sample particles, which enhance heat transportation easily within its internal component atoms. The heat conductivity of the trunk samples from the environmental temperature changes increased with the increase in the temperature across all samples.

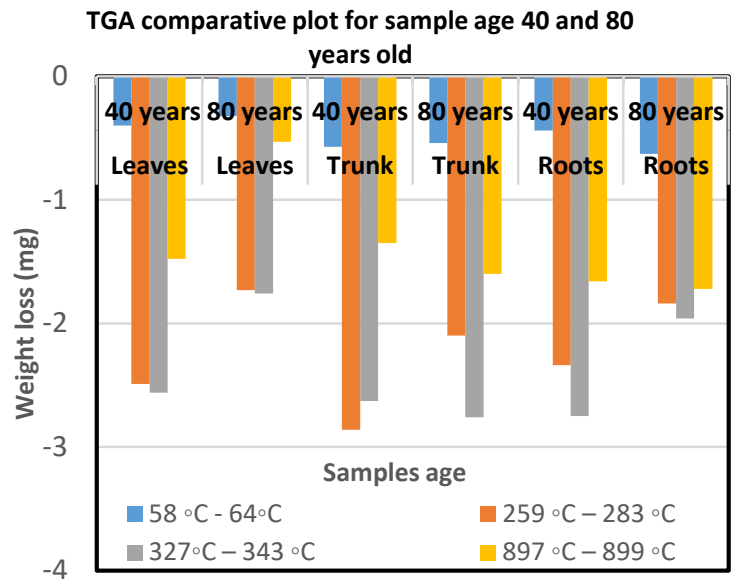

(a)

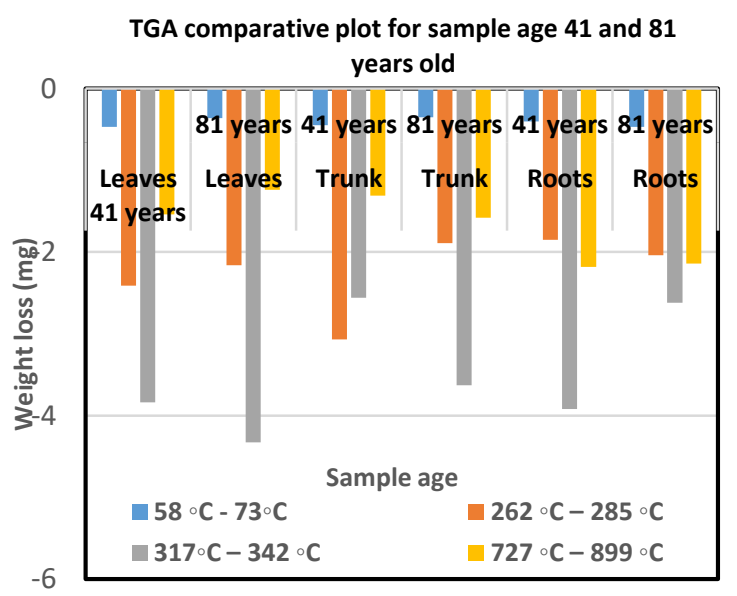

(b)

Figure 5. Comparative analysis plots of samples (a) 40 and 80 years, (b) 41 and 81 years.

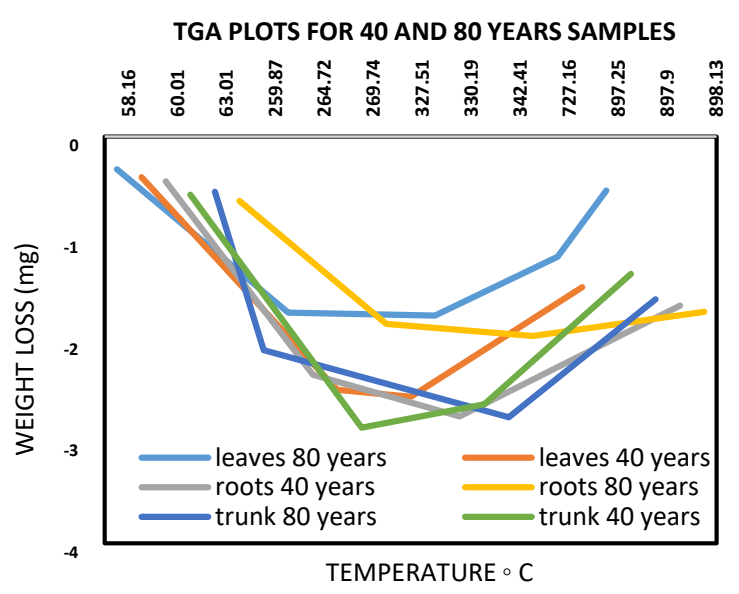

(a)

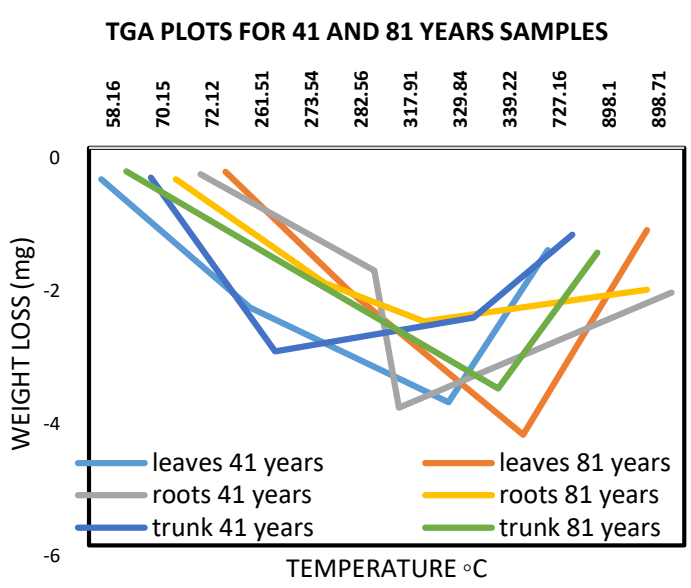

(b)

Figure 6. Weight loss against temperature changes (a) 40 and 80 years (b) 41 and 81 years.

In addition, the ages of the DPT from where each sample was taken also contributed significantly. Older aged (80 and 81 years) DPT samples have the highest diffusivity rate across all the temperature ranges applied for the laboratory test. This is due to the reduced molecular bonding within the component atoms as compared to samples from younger aged trees of 40 and 41 years old, respectively. Aside from the fewer moisture contents, this is an indication that older trunk samples tend to easily 
conduct heat due to less internal molecular bonds within its atoms, which enhance the ease of fire conductions when in contact with any fire sources. The rate of diffusivity behaviours of each sample across all ages with respect to temperature changes are displayed in Figure 7(b).

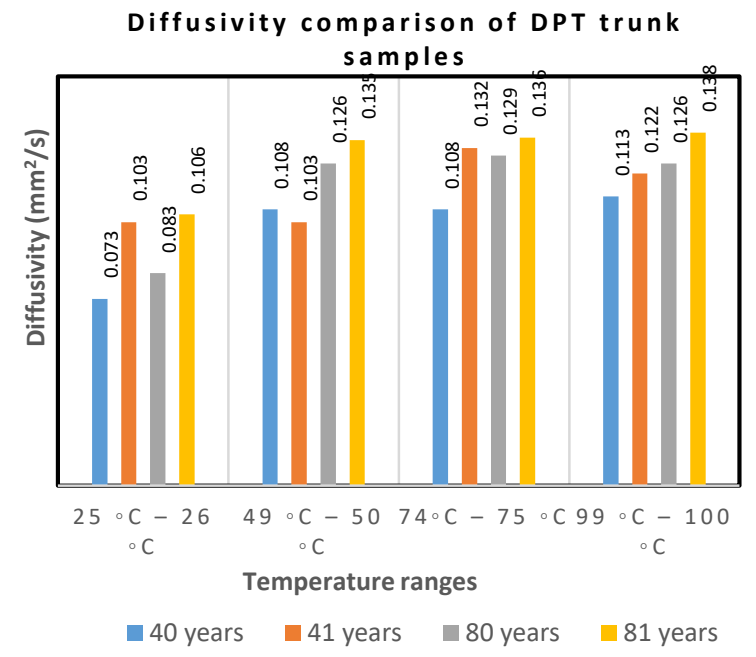

(a)

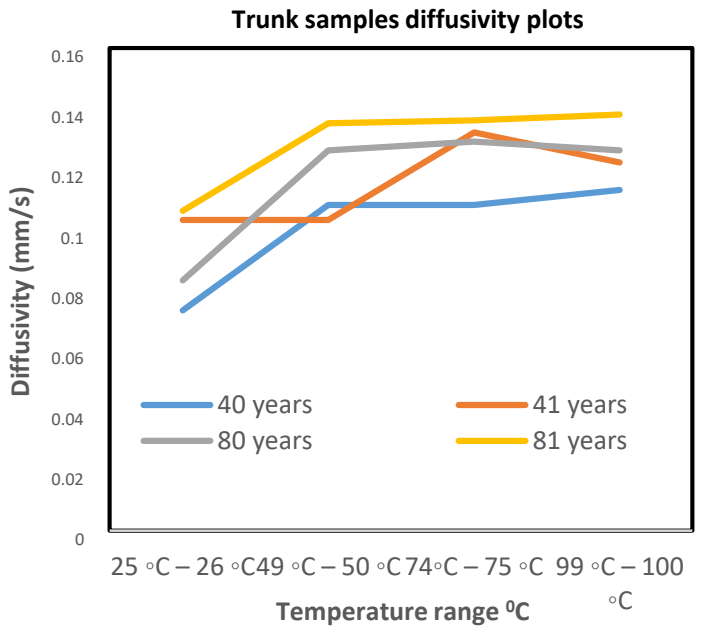

(b)

Figure 7. Diffusivity rate $\left(\mathrm{mm}^{2} / \mathrm{s}\right)$ against temperature.

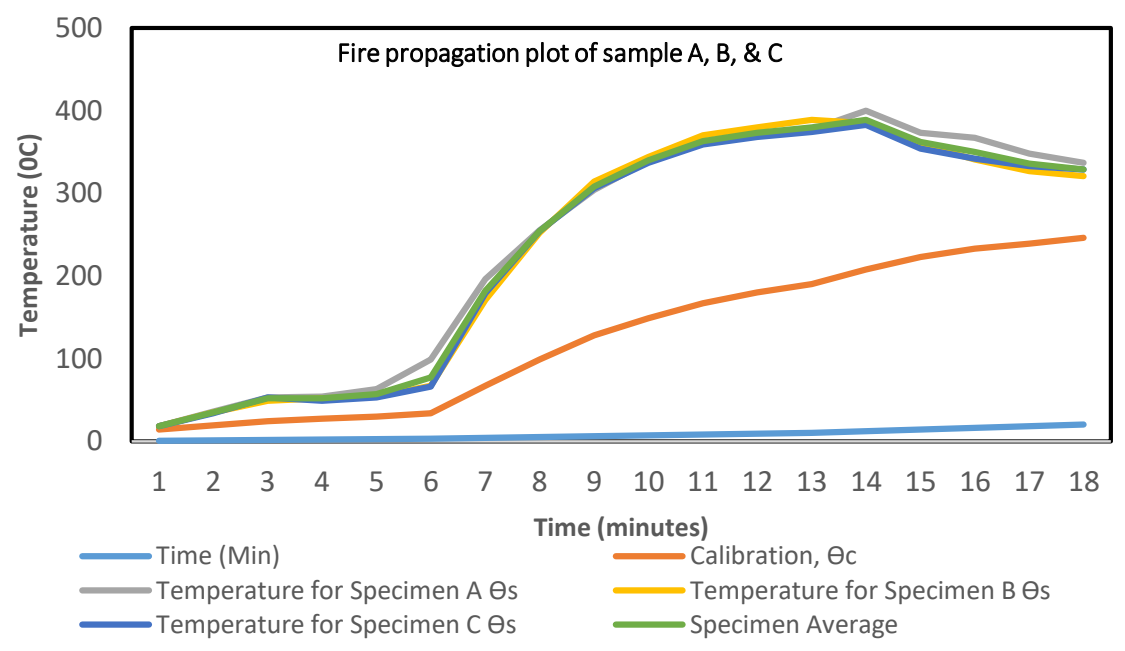

Figure 8 . Fire propagation of samples from 81 years old DPT.

\section{Propagation Test Result of DPT Samples}

The result obtained from the fire propagation test analysis for three sets of twig samples from DPT of 81 years of age selected is displayed in Table 3. This result displays the measurement obtained across the selected specimen A, B, and C. The sub-index calculation, the index performance, and fire propagation index calculation are executed with the application of Eqs. (6)-(13). The obtained result from the thermocouple reading against the calibrated temperature is displayed in Figure 8. This shows a similar linear increase in the fire propagation properties above the room calibrated ambient temperature across all the three samples with index performance values of 32.3, 29.8, and 29.4 for samples A, B, and C, respectively. The obtained average specimen value of 30.5 was 
calculated. All samples' temperature increased linearly within the first 6 min to almost $100{ }^{\circ} \mathrm{C}$, while a sudden increment in the conducted temperature from $100{ }^{\circ} \mathrm{C},-400{ }^{\circ} \mathrm{C}$ within the next $8 \mathrm{~min}$ was far above the calibrated room temperature. The fire propagation index of 0.0463 was recorded across the samples.

\section{CONCLUSIONS}

The above characterisation analysis result of the DPT samples applied as traditional building material in Libya was proven to have poor thermal resistance to heat based on the high calorific energy values obtained from a small unit mass of the trunk samples and a very high degradation weight loss at low temperature range of between $45-123^{\circ} \mathrm{C}$ value leading to fast decomposition, thereby contributing more to the fire load in any fire accident. The internal composition structure of the trunk roofing material permits ease of heat transfer based on environmental temperature changes with the highest diffusivity value of $0.138 \mathrm{~mm}^{2} / \mathrm{s}$ obtained between $99-100{ }^{\circ} \mathrm{C}$ due to the loss molecular bonding within its atoms. This aids the fast fire propagation features established with the fire propagation index at the lowest room temperature of $29.8{ }^{\circ} \mathrm{C}$ is an indication of heat transmission within the twig sample. These fire characteristics of DPT in this research have provided useful information on the DPT rate of heat conductivity, fire propagation properties, and thermal behaviours, which may be useful for fire impact assessment prediction analyses of a fire accident in traditional Libya houses. This study also provides an appropriate fire safety preventive measure based on knowledge awareness and safe practice compliance with the world standard for future work.

\section{AKNOWLEDGEMENTS}

The authors would like to appreciate the Department of Mechanical and Manufacturing Engineering, Faculty of Engineering, of the Universiti Putra Malaysia. For providing laboratory facilities and financial assistance for this research work.

\section{REFERENCES}

[1] Black WZ. Smoke movement in elevator shafts during a high-rise structural fire. Fire Safety Journal. 2009;2009:168-82.

[2] Yassine E, Mejdi J, Sophie D, Gwenaëlle T, Rachid S. Evaluation of date palm residues combustion in fixed bed laboratory reactor: A comparison with sawdust behaviour. Renewable Energy. 2014;2014:209e15.

[3] ZHANG Q-s, WEI H-y. The Characteristic Fire Protection Design of Mountainous City and Hillside Building - Illustrated by the Example of Chongqing. Procedia Engineering. 2011;2011:701-9.

[4] Tomoaki N, Takeyoshi T, Akihiko H. An evaluation method for the urban postearthquake fire risk considering multiple scenarios of fire spread and evacuation. Fire Safety Journal. 2012;2012:167-80.

[5] Jing X, Chongfu H. Fire risk analysis of residential buildings based on scenario clusters and its application in fire risk management. Fire Safety Journal. 2013;2013:72-8.

[6] Donggoo S, Dongeun K, Bongchan K, Youngjin K. An experimental study on the combustibles investigation and fire growth rate for predicting initial fire behavior in building. Procedia Engineering. 2013;2013:671 - 9 . 
[7] Martin F, Beom-Seon J, Yanlin J. A parametric study on the use of passive fire protection in FPSO topside module. Int $J$ Nav Archit Ocean Eng. 2014;2014:826 39.

[8] Anthony CYY, Guan HY, Bob A, Cook M. Fire scene investigation of an arson fire incident using computational fluid dynamics based fire simulation. Building Simulation. 2014;2014.

[9] Brian YL, Sean PH, Mark W, Usman S. Modeling fire growth in a combustible corner. Fire Safety Journal. 2003;2003:771-96.

[10] Mari-Louise P, Arne R, Maria W. Influence of window size on the energy balance of low energy houses. Energy and Buildings. 2006;2006:181-8.

[11] Jonatan G, Haukur I, Anders L, Håkan F, Michael S. Performance-based design of road tunnel fire safety: Proposal of new Swedish framework. Case Studies in Fire Safety. 2014;2014:18-28.

[12] LIU J, CHOW WK. Determination of fire load and heat release rate for high-rise residential buildings. Procedia Engineering. 2014;2014:491 - 7.

[13] Dan Nortoft S, Lars Kollgaard V. Modelling low and heat transfer around a seated human body by computational liquid dynamics. Building and Environment. 2003;2003:753-62.

[14] Lu“ X-c, Yang J-g, Zhang W-g, Huang Z. Effect of cetane number improver on heat release rate and emissions of high speed diesel engine fueled with ethanoldiesel blend fuel. Fuel. 2004;2004:2013-20.

[15] Alex B. An Overview of Design Fires for Building Compartments. Fire Technology. 2008:167-84.

[16] Zhou B, Zhou X-m, Chao M-y. Fire protection of historic buildings: A case study of Group-living Yard in Tianjin. Journal of Cultural Heritage. 2012;2012:389-96.

[17] Juan PH, Stephen W, José LT. Performance criteria for the fire safe use of thermal insulation in buildings. Construction and Building Materials. 2015;2015:285-97.

[18] Gianluca DS, Mario F. Risk-based optimisation of fire safety egress provisions based on the LQI acceptance criterion. Reliability Engineering and System Safety. 2016;2016:339-50.

[19] Xinfeng L, Xueqin Z, Bo L. Numerical simulation of dormitory building fire and personnel escape based on Pyrosim and Pathfinder. Journal of the Chinese Institute of Engineers. 2017;2017:2158-7299.

[20] Hadjisophocleous G, Jia Q. Comparison of FDS Prediction of Smoke Movement in a 10-Storey Building with Experimental Data. Fire Technology. 2009;2009:163-77.

[21] Donghyun R, Atila N. Transport of particulate and gaseous pollutants in the vicinity of a human body. Building and Environment. 2009;2009:1840-9.

[22] Black WZ. COSMO - Software for designing smoke control systems in high-rise buildings. Fire Safety Journal. 2010;2010:337-48.

[23] Yassine Em, Mejdi J, Sophie D, Gwenaelle T, Rachid S. Experimental investigation on gaseous emissions from the combustion of date palm residues in laboratory scale furnace. Bioresource Technology. 2013;2013:94-100.

[24] Azhakesan A, Shields TJ, Silcock GWH. Developments on the Fire Propagation Test. . Fire Safety Science. 2012:349-60.

[25] Azuin R, Zainal AA, Mohd Idrus MM. Safety and Health Factors Influencing Performance of Malaysian Low-Cost Housing: Structural Equation Modeling (SEM) Approach. Procedia - Social and Behavioral Sciences. 2014;2014:475 82. 
[26] Yuen ACY, Yeoh GH, Alexander R, Cook M. Fire scene reconstruction of a furnished compartment room in a house fire. Case Studies in Fire Safety. 2014;2014:29-35.

[27] Ahmad A, Ahmad MH, Khalifa A-K. Characterization of treated date palm tree fiber as composite reinforcement. Composites: Part B. 2009;2009:601-6.

[28] Shyam SS, Ashok KS, Bhesh RB. A new method of producing date powder granules: Physicochemical characteristics of powder. Journal of Food Engineering. 2008;2008:416-21.

[29] Yang X, Chen S, Gao S, Li H, Shi Q. Construction of a rotating-bomb combustion calorimeter and measurement of thermal effects. Instrumentation Science \& Technology. 2002;3:311-21.

[30] Ines M-G, Samia B, Abir M, Sabine D, Hamadi A, Christophe B, et al. Effect of ultrafiltration process on physico-chemical, rheological, microstructure and thermal properties of syrups from male and female date palm saps. Food Chemistry. 2016;2016:175-82.

[31] Alireza D, Sara MA, Mariam AA-M, Azman H, Mat UW. Mechanical and thermal properties of date palm leaf fiber reinforced recycled poly (ethylene terephthalate) composites. Materials and Design. 2013;2013:841-8.

[32] Yassine Em, Mejdi J, Sophie D, Gwenaelle T, Rachid S. Study on the thermal behavior of different date palm residues: Characterization and devolatilization kinetics under inert and oxidative atmospheres. Energy. 2012;2012:702e9.

[33] Hani HS, Ahmad H, Arshad AS, Farid NA. Pyrolysis and combustion kinetics of date palm biomass using thermogravimetric analysis. Bioresource Technology. 2012;2012:382-9.

[34] Hamdy I, Mahmoud F, Hassan M, Sherif M. Characteristics of starch-based biodegradable composites reinforced with date palm and flax fibers. Carbohydrate Polymers. 2014;2014:11- 9 .

[35] Nehdi I, Omri S, Khalil MI, Al-Resayes SI. Characteristics and chemical composition of date palm (Phoenix canariensis) seeds and seed oil. Industrial Crops and Products. 2010;2010:360-5.

[36] Khiari R, Mhenni MF, Belgacem MN, Mauret E. Chemical composition and pulping of date palm rachis and Posidonia oceanica -A comparison with other wood and non-wood fibre sources. Bioresource Technology. 2010;2010:775-80.

[37] Boudjemaa A, Adel B, Abderrahim B, Laurent I, Magali F. Renewable materials to reduce building heat loss: Characterization of date palm wood. Energy and Buildings. 2011;2011.

[38] Khadija MZ, Deepalekshmi P, Mariam AAA-M. Date palm fibre filled recycled ternary polymer blend composites with enhanced flame retardancy. Polymer testing. 2017;2017:341-8.

[39] Keramat Jahromi M, Jafari A, Rafiee S, Mohtasebi SS. A survey on some physical properties of the Date Palm tree. Journal of Agricultural Technology 2007;2:31722.

[40] Mohamad RI, Zulkiflle L, Mohd Sapuan S, Mohd Zaki AR, Mohd Khairun AU, Akhtar R. IFSS, TG, FT-IR spectra of impregnated sugar palm (Arenga pinnata) fibres and mechanical properties of their composites. J Therm Anal Calorim. 2012;2012:1375-83.

[41] Ishak MR, Sapuan SM, Leman Z, Rahman MZA, Anwar UMK. Characterization of sugar palm (Arenga pinnata) fibres. J Therm Anal Calorim. 2012;2012:981-9. 